\title{
Mi memoria de José Luis Aranguren
}

\author{
AMELIA VALCÁRCEL
}

Mi memoria directa de José Luis Aranguren sólo se remonta a los últimos veinte años. Naturalmente había oído hablar de él, e incluso yo lo había hecho, desde mi entrada en la universidad. Aclaro que mal. En estos tiempos en los que la memoria del franquismo está siendo dulcificada, casi nadie quiere o sabe reconstruir en qué consistía aquello a lo que se llama «dictadura». No era un estado de cosas pavoroso, sino cotidiano, de muchos miedos que no se exteriorizaban. Por lo mismo el valor no era apreciado. Aranguren no se manifestaba con imprudencia o como un desaforado. Si se leen sus textos son comedidos, con sus notas de ironía criptica. Pero no iba con su natural transigir con aquel estado de cosas y esto se hacía patente en sucesivas tomas de postura francas y calmadas que huían de disfrazarse del barroquismo al uso. Quiero decir que cuando Aranguren deseaba informar de algo, como en el caso de su texto Ética y política, no se acogía a la práctica de comenzar por una cuestión abstrusa, desarrollarla confusamente y proponer un par de equívocos que hicieran suponer a sus lectores que estaba en el secreto. Franco era un secreto a voces. No hace esto nunca. Desarrolla la cuestión que propone con la mayor claridad posible e informa de cómo, con quién y dónde se puede pensar con libertad y justeza. No se amparaba tampoco en las terminologia de los -ismos del progrerío. Hablaba directamente desde una tradición española que no se dejaba sofocar y aportaba a ella las visiones contrastadas del pensamiento mundial. Era claro y hasta sencillo. Si el valor en aquel panorama estaba mal visto, aliado con la sencillez, escocía. Aranguren era distinto: no se dejaba engañar y no engañaba.

Muerto ya el dictador, recuerdo un coloquio en televisión en que Aranguren fue lapidario con el par de falangistas que, supongo por pretensión de imparcialidad, le tocaron de contertulios. A toro pasado, aquellas personas, aproximadamente de su edad, insistían en contar con todo lujo de exceso retórico las bondades de la forma política totalitaria. Aquellos cuarenta años habían estado muy bien y su único defecto era no haber llevado hasta el fondo tesis políticamente tan correctas como la verticalidad de los sindicatos, el liderazgo ideológico del fundador extinto, la ausencia de partidos políticos disgregadores y el control absoluto estatal de la producción y la economía. Así lo explicaba muy convencido uno de los antiguos jerarcas insitiendo en hacer quiasmos y retruécanos sobre la voluntad y la unidad. Aranguren se encaró con él verdaderamente enfadado y le espetó: «Yo he venido aquí a hablar de política normal, no a aguantarle a usted los discursitos que usted hacía cuando podía.» Aquél había sido en efecto un discurso único, hasta la trivialidad. En ese paisaje 
de emergencia en el que el discurso único se reservaba todo el espacio, to fácil era amanecer en un extremo. Por eso lo que más encorajinaba a sus enemigos era la constante reivindicación práctica que Aranguren hacía de los terrenos medios. A sus enemigos franquistas porque su templanza los colocaba en su verdadero lugar: derecha extrema gobernante. A algunos elementos difícilmente clasificables del progrerío porque nunca compartía su radicalidad aparente. Y encima podía. No faltó quien atribuyera su valor a su acomodada fortuna. «Así cualquiera.» Se podía hasta permitir el lujo de ser expulsado de la Universidad. La envidia hace estos juicios. Desde la derecha el odio lo señalaba como un compañero de viaje de la anti-España, amargado, porque había traicionado a los suyos. Algún personajillo de la izquierda prefería cebarse en su cristianismo o en su claridad.

Desde luego Aranguren en su vida no tuvo malas relaciones con la fortuna. $Y$ estaba bastante contento de ello. Hasta usaba la picardía y se le animaban los ojuelos recordando sus éxitos juveniles con las chicas, propiciados no precisamente por su figura (era feo a decir basta, aunque resultón), sino un bólido regalo de su padre en la época de España en que la mayor parte de la población tenía con el burro relaciones mucho más estrechas. Una confortable situación inicial, un providencial diagnóstico de una tisis inexistente, una finca en Ávila para curársela y la lectura, entonces, de dos filósofos, le engranaban con una tradición filosófica creyente pero laica, alejada de la escolástica de los Seminarios. $\mathrm{Y}$ un temperamento poco gregario y un punto displicente le apartó de elegir amigos dentro del nacionalcatolicismo y sus abrevaderos.

Esto, como digo, le creó enemigos sobre la marcha, pero fue una fortuna para él y para quienes enseñó. Tanto citar «enemigos» puede falsear el rasgo fundamental de su suerte: le gustaba mucho que le quisieran y fue muy querido. Incluso por gentes que no conocían nada más que su personalísima figura a través de los medios. Pasear con él lo probaba. Los desconocidos se paraban a saludarle, la gente le abordaba en los lugares públicos, incluso agitaban las manos desde las ventanas. Acompañarle a un restaurante tenía dos ventajas. La prontitud y delicadeza del servicio y ración doble de lo que uno prefiriera. En punto a gustos gastronómicos se dejaba aconsejar y no comía prácticamente nada, de modo que repartía con generosidad lo que su diligente invitada - en mi caso- le hubiera sugerido. Tales argucias le ponían de buen humor, si bien tengo la sospecha de que las encontraba sólo divertidas en el sexo femenino, porque, y a pesar de su feminismo explícito, estaba dotado de lo que podíamos llamar una misoginia galante.

Estas facetas de su carácter brillaban más en lugares como Laredo, donde tenía un curso anual de verano que disfrutaba especialmente. Allí él, que en su trato era muelle aunque reservado, se soltaba algo más. Tomaba camparis generosos, recordaba historias juveniles y se ponía unas camisas que le habia dibujado Romeu a modo de enseña de su disposición básica para tales días. Ver a Aranguren de espaldas luciendo un «Manolito, jefe de la liga de los-sin-ba- 
ta», cuando acababa de recordar que de niño en los Jesuitas había sido Príncipe, tenía bastante gracia.

En tales ocasiones y aun en otras tenia un talante de consentidor asombroso. El apoyo de todas las causas, el primer firmante de todos los manifiestos. Lo sé bien porque le presenté varios. Llegaba a entrar la duda de si no era una especie de coquetería. ¿Dónde estaba el núcleo duro de una persona que nunca se negaba a asistir a un acto y simpatizaba con todas las causas minoritarias? Para encontrarlo había que cabrearle. Y era difícil de cabrear en la relación amistosa y cortés. Pero insistiendo, incluso con años de insistencia, se lograba. Tengo solamente una experiencia de ello, pero me trae muy contenta. Descubri un Aranguren apodíctico que, sobre el terreno, me dijo que el mayor filósofo del siglo xx era Heidegger, que Wittgenstein era un tartamudo filosófico y que Kierkegaard era una especie de teólogo pero no llegaba a filósofo. Y todo ello verdaderamente colérico. Pongo a Magdalena Mora por testigo. Fue en el año 1992 y estábamos disfrutando de la caída de la tarde en un café de La Coruña tras haber hecho una excursión marina en la que él había ejercido de capitán de lancha rápida. Quizá lo del dominio de las olas le había puesto en fase asertiva. Porque no parecía gustar de enfadarse con casi nadie. Sin embargo, descubri en aquella ocasión que tenía enfados estupendos.

Conocida la receta, se la apliqué, en alguna otra, para ver de sacarlo de su melancolía en su última enfermedad. Bastaba con mentarle en solfa el sacrosanto nombre de Heidegger, a veces con la añadida sevicia de acompañarlo del de Zubiri, para que se enfadara y esto le devolvía el tono. Me funcionó hasta mi última entrevista con él, en su casa de la sierra, a escasos meses de su muerte. Por la segunda ley de Thorndike («todo animal que adquiere una habilidad gusta de practicarla») saqué a Heidegger y Zubiri al coso, pero no apartó los ojos molesto. Me cogió las manos y me dijo: «Todo eso es la teoría, pero lo importante es la vida.»

La vida que veía marcharse cuando se le deshilvanaba la memoria concreta de las calles, de los nombres de las personas, de los días. Previamente habíamos coincidido en la entrega del Premio «Príncipe de Asturias» del año 1995. Reunió sus fuerzas para acudir a recogerlo y se presentó acompañado de su hija Pilar, preparado para pasar un día largo y trabajoso. Fuc afable con la prensa y cariñoso con los amigos más jóvenes que le acompañábamos. Durante la recepción se apoyaba en nosotros, y tanto, que alguno sugirió que tal fervor había que atribuirlo a la falta de sillas. Le buscamos una con algún incidente de protocolo. Pero tampoco sentado quería soltarnos. Creo que no era ni el merecido honor ni la fragilidad de su salud lo que le colocaba en aquella blandura sentimental. Discretamente reía las bromas, daba suaves palmadas y abrazos largos y calmados. Era probablemente el amor de la vida manifestándose sin el severo pudor que siempre exige. Aquel maestro, que en palabras del Príncipe Felipe shabía realizado la dificil tarea de educir para todos pensamiento, la energía más sutil y necesaria de cuantas existen», ahora decía: «ven», "acércate», «dame la mano». 
La noche en que Aranguren iba a morir yo estaba en Madrid. Mi avión salía a la tarde y sin saber por qué dudé mucho en cogerlo. Era como si tuviera que vencer una resistencia, desconocida y fuerte. Tenemos los kantianos, los kantianos verdaderos, una gran práctica en vencer estas resistencias y sobreponer a cualquier intuición el término «deber» escrito en letras de papelón dorado. Así que, como era mi deber, tomé el avión. Tuve la impresión de que tardaba en levantarse y lo hacía dando tumbos. Cuando pasábamos sobre la sierra de Madrid se levantó de ella un aire rojo y turbio. Un mal aire. $\mathrm{Y}$ de nuevo tuve la impresión de que aquel mal aire algo tenía que ver conmigo, pero simplemente la guardé, desazonada. Al día siguiente y muy de mañana una querida discípula me telefoneó para decirme que Aranguren había muerto. El aire aquel se lo había llevado.

El maestro que yo conocí personalmente por primera vez en la Semana de Ética de la UNED, de mano de Javier Muguerza, el profesor que en la lectura y defensa de mi tesis doctoral me enseñó la profunda diferencia entre lo serio y lo formal, el firmante de mis manifiestos, el conferenciante de mis causas, el caballero gentil en los convites, la voz al otro lado del teléfono, todos ellos en uno, ya no estaban. $Y$ sus libros dejan sólo adivinar un poco de su personalísimo talante, pues se vuelcan mucho más en el empeño de dotarnos de civilidad y sentido del matiz. Pero hasta tal punto ha sido Aranguren una referencia común española, su modo de estar en el mundo, un modelo para muchos, en fin, hasta tal punto parte de su talento fue su talante, que su obra no parece, de momento, poder llenar el vacío de su ausencia. Para que nos reconciliemos con la docta claridad de su abundante obra, su recuerdo personal tendrá que, probablemente, oscurecerse. Así sucede siempre con los que inician grandes cosas. 